\title{
Clinical predictors of successful vaginal myomectomy for prolapsed pedunculated uterine leiomyoma
}

\author{
(D) Serdar Aydın ${ }^{1}$, (D) Hale Göksever Çelik², (D) Mustafa Maraşlı ${ }^{1}$, (D) Rabia Zehra Bakar \\ 1Department of Obstetrics and Gynecology, Bezmialem Vakıf University School of Medicine, İstanbul, Turkey \\ 2Department of Obstetrics and Gynecology, Saglik Bilimleri University, İstanbul Kanuni Sultan Süleyman Training and \\ Research Hospital, İstanbul, Turkey \\ 3Department of Obstetrics and Gynecology, Erbaa State Hospital, Tokat, Turkey
}

\section{Abstract}

Objective: Uterine leiomyomas are the most common pelvic tumor in women. The calculated prevalence of prolapsed pedunculated leiomyoma was $2.5 \%$ in patients who underwent surgery. Although vaginal removal is safe and effective, hysterectomy demand is questionable. We aimed to analyze the association between patient characteristics, clinical features of prolapsed pedunculated submucosal leiomyoma, and the probability of successful vaginal myomectomy.

Material and Methods: This study was conducted in 35 women who presented with prolapsed pedunculated uterine leiomyoma. Patients were grouped according to the treatment procedure, either vaginal myomectomy or hysterectomy.

Results: Hysterectomy was performed in 14 patients and vaginal myomectomy was performed in 21 women. The mean ages and menopausal status were similar. Parity was higher in the hysterectomy group $(\mathrm{p}=0.02)$. The preoperative hematocrit value of patients undergoing vaginal myomectomy was significantly lower $(p=0.04)$. There was no significant difference between the groups regarding the largest leiomyoma diameter. However, the median calculated leiomyoma volume was lower in the vaginal myomectomy group $(p=0.04)$. None of the variables were independently associated with successful vaginal myomectomy on multivariable logistic regression analysis.

Conclusion: The feasibility and choice of vaginal myomectomy is associated with low parity, absence of coexisting leiomyoma, high volume of leiomyoma estimated via ultrasound measurement, and severe anemia. (J Turk Ger Gynecol Assoc 2018; 19: 146-50)

Keywords: Leiomyoma, prolapsed pedunculated submucosal leiomyoma, vaginal myomectomy, hysterectomy

Received: 13 November, 2017 Accepted: 2 February, 2018

\section{Introduction}

Uterine leiomyomas are the most common pelvic tumor in women arising from the smooth muscle of the myometrium (1). Leiomyomas are classified according to their location within the myometrium. Prolapsed pedunculated submucous myoma is classified as type 0 submucous leiomyoma (2). In general, the prevalence of uterine leiomyoma is approximately $25 \%$ of reproductiveaged women and submucosal leiomyoma account for approximately $15-20 \%$ of these (3). The real prevalence of prolapsed pedunculated submucosal myoma is unknown but the calculated prevalence was $2.5 \%$ in patients who underwent surgery for leiomyoma (4). They typically present with vaginal bleeding, pelvic pain that is generally cramping in nature during the expulsion of the myoma from the cervix, and dysmenorrhea and bloody discharge. Surgery is recommended for symptomatic patients. Although vaginal removal is safe and effective for uterine prolapsed pedunculated leiomyoma, hysterectomy demand is questionable (4-6).

Few series in the English literature about the management of uterine prolapsed pedunculated submucous myomas have been reported (4-9). However, this report mainly addresses the early results, complications, and feasibility of vaginal removal. There is an evidence gap regarding how patient characteristics and leiomyoma features influence the choice of operative procedures. Better understanding of factors that influence the 
probability of undergoing hysterectomy would help deliver patient-centric uterine leiomyoma care. The aim of this study was to analyze the association of patient characteristics and the probability of hysterectomy and the results of the two procedures in patients with prolapsed pedunculated submucosal myoma.

\section{Material and Methods}

This retrospective cross-sectional study was based on the analysis of medical records of 35 women who presented with prolapsed pedunculated uterine leiomyoma. We reviewed the hospital records of all patients admitted to departments of gynecology of two centers with a clinical diagnosis of prolapsed pedunculated submucous myoma between November 2011 and March 2016. The local ethics committee approved the study.

Demographic, clinical and pathologic data, including age, gravidity, parity, history of uterine surgery and cesarean section, smoking status, menopausal status, medical history, complications, and preoperative and postoperative hematocrit were all retrieved from the medical records. A history of medical conditions, including hypertension, diabetes mellitus, hypercholesterolemia and thyroid disease were recorded if hospital records confirmed the diagnosis. Patients with amenorrhea for more than one year since the last menstrual period were considered to be menopausal.

Only myomas with a pedicle base originating at or above the level of the internal cervical os were included. There was a total of 35 patients during the study period. Patients were grouped according to the performed procedure; either vaginal myomectomy or hysterectomy. Vaginal myomectomy was performed with general anesthesia under sterile conditions. The myoma was grasped using tenaculum forceps under direct vision and twisted around its pedicle. Too much downward traction on the myoma was avoided so as not to cause inversion of the uterus. In some cases, when feasible, the pedicle was clamped and ligated as high as possible. Myomectomy was successfully accomplished without dilatation of the cervix. Total abdominal hysterectomy with or without concomitant bilateral salpingo-oophorectomy were performed using a standard clamp technique as performed in benign gynecologic indications. All patients in whom hysterectomy was performed were decided at the beginning of the patients' examinations. If laparoscopic hysterectomies were performed, vaginal removal of the leiomyoma was performed first to place the uterine manipulator.

\section{Statistical analysis}

Data are expressed as mean \pm standard deviation or number and percentage, median and range, as appropriate. Statistical analysis was performed after normality testing (histogram analysis and/or Kolmogorov-Smirnov) using IBM SPSS version 22. Student's t-test was used for comparisons of normally distributed variables, and the Mann-Whitney U test was used for categorical variables. Chi-square and Fisher's exact tests were used to compare the proportion of categorical variables. Multivariable logistic regression models were developed to predict the probability of successful vaginal removal of a prolapsed pedunculated leiomyoma using variables identified during univariate analysis. Odds ratios with 95\% confidence intervals were also calculated. The Statistical Package for Social Sciences (SPSS) for Windows version 22.0 (SPSS Inc., Chicago, IL, USA) was used for the analysis and two-sided $\mathrm{p}$ value of $<0.05$ was considered as significant.

\section{Results}

Vaginal myomectomy was successful in 21 women. Hysterectomy for prolapsed pedunculated submucosal leiomyoma was performed in 14 patients. The mean age of the study population was $46.1 \pm 8$ years (range, $29-62$ years). Parity was $2.7 \pm 1.7$ (range, $0-7$ ). Two women were nulliparous (5.7\%) and one was nulligravida (2.8\%). Only 4 women were in the postmenopausal period (11.4\%). The patient characteristics, laboratory and imaging features of patients undergoing vaginal myomectomy or hysterectomy for prolapsed pedunculated vaginal leiomyoma are presented in Table 1 . The mean ages were $44.8 \pm 9.2$ and $47.9 \pm 5.4$ years in the vaginal myomectomy and hysterectomy groups, respectively. The mean parity of the hysterectomy group was statistically higher than the uterus-sparing group $(3.6 \pm 1.6$ vs $2.1 \pm 1.6, p=0.02)$. All of the hysterectomy group patients were parous and $2(9.5 \%)$ women in the vaginal myomectomy group were nulliparous $(p=0.2)$. One woman $(7.1 \%)$ in the hysterectomy group and 3 women (14.3\%) in the vaginal myomectomy group were postmenopausal $(p=0.5)$. Also, comorbidity profiles of the patients in both groups were similar.

On admission, hematocrit value of the patients undergoing vaginal myomectomy $(29.9 \pm 5.2)$ was significantly lower than those undergoing hysterectomy $(33.4 \pm 3.8, \mathrm{p}=0.04)$. Blood transfusion prior to surgery because of preoperative severe anemia was performed to 11 patients (52.6\%) in the vaginal myomectomy group and 5 patients (35.7\%) in the hysterectomy group $(\mathrm{p}=0.3)$

All patients who underwent vaginal myomectomy had no more than one prolapsed pedunculated leiomyoma. The total leiomyoma number in the hysterectomy group ranged from 1 to 5 with median number of $1(p=0.03)$. Median of the largest diameter of prolapsed pedunculated submucosal leiomyoma was $5 \mathrm{~cm}$ (range $2-10 \mathrm{~cm}$ ) in the vaginal myomectomy group and $5.5 \mathrm{~cm}$ (range, $3-13 \mathrm{~cm})$ in the hysterectomy group $(\mathrm{p}=0.2)$. 
The median leiomyoma volume was $60 \mathrm{~cm}^{3}$ (range, 24-660 $\mathrm{cm}^{3}$ ) in the vaginal myomectomy group and $112 \mathrm{~cm}^{3}$ (range, $\left.40-910 \mathrm{~cm}^{3}\right)$ in the hysterectomy group $(\mathrm{p}=0.04)$.

Multivariable logistic regression models were developed to predict hysterectomy using variables parity, preoperative hematocrit value, leiomyoma number, and estimated leiomyoma volume, which were identified during the univariate analysis (Table 2). None of the variables were independently associated with successful vaginal myomectomy or those undergoing hysterectomy.

The mean duration of hospitalization in women who underwent hysterectomy was $6.7 \pm 3$ days, whereas the duration was $3.5 \pm 3$ days in the vaginal myomectomy group $(p=0.005)$. The mean postoperative hospital stay durations were $1.7 \pm 1.4$ days in vaginal myomectomy group and $3.1 \pm 1.6$ days in hysterectomy group. However, the overall hospitalization (4 days, $p=0.7$ ) and the postoperative hospitalization $(2 \pm 0.8, \mathrm{p}=0.7)$ for the small subgroup of laparoscopic myomectomy were similar to vaginal myomectomy. Postoperative hematocrit values were similar. We did not encounter any major complications except a case of febrile morbidity seen after vaginal removal because of abrupt bleeding controlled with pedicle ligation.

\section{Discussion}

The preference of vaginal removal or hysterectomy in patients with prolapsed pedunculated submucosal leiomyoma depends on many factors. There is an association between patient characteristics and the choice of management. Younger age and parity, lower preoperative hematocrit levels, smaller leiomyoma diameter and volume were observed in the vaginal myomectomy group, which resulted in shorter hospitalization time and postoperative hospitalization duration.

Table 1. Demographic, baseline characteristics and clinical features of patients in vaginal myomectomy and hysterectomy

\begin{tabular}{|c|c|c|c|}
\hline & $\begin{array}{l}\text { Vaginal myomectomy } \\
(n=21)\end{array}$ & $\begin{array}{l}\text { Hysterectomy } \\
(n=14)\end{array}$ & $\mathbf{p}$ \\
\hline Age, years (mean $\pm \mathrm{SD}$ ) & $44.8 \pm 9.2$ & $47.9 \pm 5.4$ & 0.2 \\
\hline Gravidity (mean $\pm \mathrm{SD})$ & $4.4 \pm 2.7$ & $4.6 \pm 1.7$ & 0.1 \\
\hline Parity (mean \pm SD) & $2.1 \pm 1.6$ & $3.6 \pm 1.6$ & 0.02 \\
\hline Nulliparity [n (\%)] & $2(9.5)$ & 0 & 0.2 \\
\hline Menopause status [n (\%)] & $3(14.3)$ & $1(7.1)$ & 0.5 \\
\hline Comorbidty [n (\%)] & $5(23.8)$ & $7(50)$ & 0.1 \\
\hline Previous uterine surgery [n (\%)] & $5(23.8)$ & $4(28.6)$ & 0.7 \\
\hline Previous myomectomy [n (\%)] & $2(9.5)$ & $1(7.1)$ & 0.5 \\
\hline Blood transfusion [n (\%)] & $11(52.4)$ & $5(40)$ & 0.8 \\
\hline Preoperative hematocrit (mean \pm SD) & $29.9 \pm 5.2$ & $33.4 \pm 3.8$ & 0.04 \\
\hline Postoperative hematocrit (mean \pm SD) & $30.4 \pm 3$ & $31.8 \pm 3.7$ & 0.3 \\
\hline Units of erytrocyte suspension transfusion (mean $\pm \mathrm{SD}$ ) & $1.2 \pm 1.9$ & $1.6 \pm 1.7$ & 0.4 \\
\hline Number of leiomyoma [median (range)] & 1 & $1(1-5)$ & 0.03 \\
\hline Concomitant intramural leiomyoma [n (\%)] & 0 & $6(42.9)$ & 0.001 \\
\hline Leiomyoma diameter, cm [median (range)] & $5(2-10)$ & $5.5(3-10)$ & 0.2 \\
\hline Leiomyoma volume, $\mathrm{cm}^{3}$ [median (range)] & $60(24-660)$ & $112(40-910)$ & 0.04 \\
\hline Hospitalization time, days (mean $\pm \mathrm{SD}$ ) & $3.5 \pm 3$ & $6.7 \pm 3$ & 0.005 \\
\hline Postoperative hospitalization duration, days (mean \pm SD) & $1.7 \pm 1.4$ & $3.1 \pm 1.6$ & 0.04 \\
\hline SD: Standard deviation & & & \\
\hline
\end{tabular}

Table 2. Multivariable logistic regression analysis of factors for the prediction of undergoing hysterectomy

\begin{tabular}{|l|l|l|l|}
\hline Parameters & Adjusted odds ratio & CI & Significance \\
\hline Parity & 1.63 & $0.86-3.08$ & 0.1 \\
\hline Leiomyoma volume & 1.01 & $0.99-1.01$ & 0.09 \\
\hline Concomitant leiomyoma & 0 & 0 & 0.9 \\
\hline Preoperative hematocrit & 1.02 & $0.80-1.31$ & 0.8 \\
\hline CI: Confidence interval & \multicolumn{2}{|l}{} \\
\hline
\end{tabular}


The least invasive management option for women with symptomatic prolapsed pedunculated submucosal leiomyoma, in other words myoma in status nascendi, was evaluated in a few retrospective studies. These studies claimed that vaginal removal of prolapsed pedunculated leiomyoma was a safe and simple procedure with shorter hospitalization and minimal morbidity (4-6). The most probable potential complications of vaginal removal of prolapsed pedunculated leiomyoma are excessive hemorrhage from the pedicle, infection, and uterine inversion due to excessive traction. However, they did not report any complications in these series. Also, in our series, we encountered no major complications except a case of febrile morbidity controlled with antipyretic treatment and a minimal surgical procedure, as mentioned before.

Vaginal removal of prolapsed pedunculated leiomyoma appears to be feasible in most cases $(5,6)$. Until now, there has been no analysis of factors to predict successful vaginal removal. Although without evidence, the widely accepted features of prolapsed pedunculated leiomyoma that cannot be removed through vaginal myomectomy are leiomyoma with broad-based pedicle, non-visualized pedicle, leiomyoma larger than $4 \mathrm{~cm}$, and cervical leiomyoma rather than submucosal. In a retrospective series of 46 women with prolapsed pedunculated leiomyoma, only two cases failed due to the difficulty of reaching the pedicle of the leiomyoma (6). Caglar et al. (10) reviewed 70 patients retrospectively. They concluded that leiomyoma diameter over $5 \mathrm{~cm}$ could not be successfully managed vaginally. They could not perform logistic regression or other statistical analysis to detect predictors, and they did not explain the rationale of choosing the diameter of $5 \mathrm{~cm}$. In another retrospective series, vaginal myomectomy, abdominal myomectomy or hysterectomy were compared in the management of prolapsed pedunculated leiomyoma, but the rate of conversion from a vaginal removal to abdominal procedure was not reported (5). Even very large leiomyomas, up to $10 \mathrm{~cm}$, were successfully removed vaginally and completed without any complications. In our vaginal myomectomy group, $62 \%$ of women had a leiomyoma diameter larger than $5 \mathrm{~cm}$. Ultrasound estimated leiomyoma volume may help to predict vaginal myomectomy on univariate analysis, but on logistic regression it loses its importance as an independent determinant.

Surgery has been the mainstay of leiomyoma treatment. Leiomyoma, irrespective of location, was reported as the most common indication for hysterectomy according to the literature (11-13). Hysterectomy has the advantages of the elimination of symptoms and no risk of recurrence. Also, significant and sustained improvements are seen for symptoms, psychological function and quality of life after hysterectomy (14). Uncertainty remains regarding how different patient characteristics are associated with uterine-sparing procedures and hysterectomy (15). The choice of procedures depends on the age of the woman, reproductive potential, accompanied diseases, and anemia. The preference for hysterectomy has decreased with infertility, higher income and education, and decreasing age (16). Furthermore, concomitant menstrual disorders, uterovaginal prolapse, and previous myomectomy history increase the need for hysterectomy (17-19). We found that low parity, preoperative anemia, and absence of coexisting leiomyomas were associated with preferences for uterinesparing surgery. Hysterectomy is usually required in women with multiple leiomyomas. Dicker et al. (5) presented a series of 142 patients managed with different methods, either vaginally or abdominally over 10 years. A total of 46 women had a vaginal myomectomy, 12 had abdominal hysterectomy, usually following vaginal removal of the prolapsed pedunculated leiomyoma, and 18 underwent vaginal hysterectomy. Riley (8) presented 41 patients, 13 were treated by abdominal hysterectomy. The authors reported that hysterectomy was related to slightly higher postoperative morbidity, but comparable to that of hysterectomy for other indications. As expected, the duration of hospitalization after vaginal myomectomy is shorter than with an abdominal operation $(5,10)$. In our series, hospital stay was longer with abdominal hysterectomy, but was comparable with vaginal removal in the small series of laparoscopic hysterectomy.

In a broad sense, the disadvantage of myomectomy is the risk of recurrence or formation of new leiomyomas. The risk of a second operation after myomectomy ranges from $11 \%$ to $26 \%(20,21)$. The detection of new leiomyomas through imaging is about $50 \%$ of women within 5 years after abdominal myomectomy (22). Although the risk of leiomyoma recurrence may be attributed to a prolapsed pedunculated leiomyoma, myoma-related symptoms appear to occur infrequently. A retrospective series of 46 women reported that $20 \%$ of cases continued to be symptomatic, $9 \%$ cases required a repeat vaginal myomectomy, and $6 \%$ had a hysterectomy at 5.5 year follow-up (4). Hysterectomy in these cases may have been performed due to indications other than the original prolapsed leiomyoma. In another series of 46 women, hysterectomy was required in an additional 14\% of patients in whom vaginal removal of prolapsed pedunculated leiomyoma was successful. The present study has several limitations; first, the retrospective design of the study and lack of follow-up of the patients, and secondly, the relatively small sample size of the study population. The strengths of our study include new data regarding the prediction of success or choice of vaginal removal for prolapsed pedunculated leiomyomas that presented with prolapse from the cervical canal with more preoperative factors than previous studies, in the setting of laparoscopic hysterectomy. 
In conclusion, both vaginal removal and hysterectomy are safe procedures for prolapsed pedunculated leiomyoma. The feasibility and choice of vaginal removal or hysterectomy depend on many factors. Lower parity, absence of coexisting leiomyoma, lower volume of presenting leiomyoma estimated via ultrasound measurement, and more severe anemia, which may be a sign that less stable hemodynamics were associated with preference of vaginal removal. However, neither of these factors predicted the operation choice or obligation independently.

\section{Acknowledgements}

We appreciate the assistance of Monica Ann Malt, a native English speaker and lecturer in Bezmialem Vakıf University, for English language editing of this article.

Ethics Committee Approval: As this work represents a retrospective chart review, the local ethics committee permission was not sought.

Informed Consent: Written informed consent was obtained from all patients who participated in this study.

Peer-review: Externally peer-reviewed.

Author Contributions: Concept - S.A., H.G.Ç.; Design - S.A., H.G.Ç.; Supervision - S.A., H.G.Ç.; Materials-M.M., R.Z.B.; Writer - S.A., H.G.Ç.

Conflict of Interest: No conflict of interest is declared by the authors.

Financial Disclosure: The authors declared that this study received no financial support.

\section{References}

1. Parker WH. Etiology, symptomatology, and diagnosis of uterine myomas. Fertil Steril 2007; 87: 725-36.

2. Munro MG, Critchley HO, Fraser IS; FIGO Menstrual Disorders Working Group. The FIGO classification of causes of abnormal uterine bleeding in the reproductive years. Fertil Steril 2011; 95: 2204-8.

3. Buttram VC Jr, Reiter RC. Uterine leiomyomata: etiology, symptomatology, and management. Fertil Steril 1981; 36: 433-45.
4. Ben-Baruch G, Schiff E, Menashe Y, Menczer J. Immediate and late outcome of vaginal myomectomy for prolapsed pedunculated submucous myoma. Obstet Gynecol 1988; 72: 858-61.

5. Dicker D, Feldberg D, Dekel A, Yeshaya A, Samuel N, Goldman JA. The management of prolapsed submucous fibroids. Aust NZ J Obstet Gynaecol 1986; 26: 308-11.

6. Golan A, Zachalka N, Lurie S, Sagiv R, Glezerman M. Vaginal removal of prolapsed pedunculated submucous myoma: a short, simple, and definitive procedure with minimal morbidity. Arch Gynecol Obstet 2005; 271: 11-3.

7. Brooks GG, Stage AH. The surgical management of prolapsed pedunculated submucous leiomyomas. Surg Gynecol Obstet 1975 141: $397-8$

8. Riley P. Treatment of prolapsed submucous fibroids. S Afr Med J 1982; 62: 22-4.

9. Sikazwe NC. Prolapsed pedunculated sub-mucous uterine fibroleiomyomata at the university teaching hospital, Lusaka. Centr Afr J Med 1994; 40: 192-4.

10. Caglar GS, Tasci Y, Kayikcioglu F. Management of prolapsed pedunculated myomas. Int J Gynaecol Obstet 2005; 89: 146-7.

11. Miller NF. Hysterectomy: therapeutic necessity or surgical racket? Am J Obstet Gynecol 1946; 51: 804-10.

12. Toma A, Hopman WM, Gorwill RH. Hysterectomy at a Canadian tertiary care facility: results of a one- year retrospective review. BMC Womens Health 2004; 4: 10.

13. Tiwana KK, Nibhoria S, Monga T, Phutela R. Histopathological audit of 373 nononcological hysterectomies in a teaching hospital. Patholog Res Int 2014; 2014: 468715

14. Kjerulff KH, Langenberg PW, Rhodes JC, Harvey LA, Guzinski GM, Stolley PD. Effectiveness of hysterectomy. Obstet Gynecol 2000; 95: 319-26.

15. Viswanathan M, Hartmann KE, McKoy N, Stuart G, Rankins N, Thieda P, et al. Management of uterine fibroids: an update of the evidence. Evid Rep Technol Assess (Full Rep) 2007: 1-122.

16. Borah BJ, Laughlin-Tommaso SK, Myers ER, Yao X, Stewart EA. Association Between Patient Characteristics and Treatment Procedure Among Patients with Uterine Leiomyomas. Obstet Gynecol 2016; 127: 67-77.

17. Lee DW, Gibson TB, Carls GS, Ozminkowski RJ, Wang S, Stewart EA. Uterine fibroid treatment patterns in a population of insured women. Fertil Steril 2009; 91: 566-74.

18. Jacobson GF, Shaber RE, Armstrong MA, Hung YY. Changes in rates of hysterectomy and uterine conserving procedures for treatment of uterine leiomyoma. Am J Obstet Gynecol 2007; 196: 601.

19. Stovall DW. Clinical symptomatology of uterine leiomyomas. Clin Obstet Gynecol 2001; 44: 364-71.

20. Malone LJ. Myomectomy: recurrence after removal of solitary and multiple myomas. Obstet Gynecol 1969; 34: 200-3.

21. Acien P, Quereda F. Abdominal myomectomy: results of a simple operative technique. Fertil Steril 1996; 65: 41-51.

22. Fedele L, Parazzini F, Luchini L, Mezzopane R, Tozzi L, Villa L. Recurrence of fibroids after myomectomy: a transvaginal ultrasonographic study. Hum Reprod 1995; 10: 1795-6. 